\title{
New tris- and pentakis-fused donors containing extended tetrathiafulvalenes: New positive electrode materials for rechargeable batteries
}

\author{
Shintaro Iwamoto ${ }^{1,2}$, Yuu Inatomi ${ }^{1,3}$, Daisuke Ogi ${ }^{1}$, Satoshi Shibayama1, \\ Yukiko Murakami ${ }^{1}$, Minami Kato ${ }^{1}$, Kazuyuki Takahashi ${ }^{4}$, Kazuyoshi Tanaka ${ }^{2}$, \\ Nobuhiko Hojo ${ }^{3}$ and Yohji Misaki ${ }^{* 1,5}$
}

\author{
Full Research Paper \\ Address: \\ ${ }^{1}$ Department of Applied Chemistry, Graduate School of Science and \\ Engineering, Ehime University, 3 Bunkyo-cho, Matsuyama, Ehime \\ 790-8577, Japan, ${ }^{2}$ Department, Molecular Engineering, Graduate \\ School of Engineering, Kyoto University, Katsura, Kyoto 615-8520, \\ Japan, ${ }^{3}$ Panasonic Corporation, 1006 Kadoma, Kadoma, Osaka \\ 571-8501, Japan, ${ }^{4}$ Department of Chemistry, Graduate School of \\ Science, Kobe University, 1-1 Rokkodai-cho, Nada-ku, Kobe \\ 657-8501, Japan and ${ }^{5}$ Elements Strategy Initiative for Catalysts and \\ Batteries (ESICB), Kyoto University, Katsura, Kyoto 615-8520, Japan \\ Email: \\ Yohji Misaki* - misaki.yohji.mx@ehime-u.ac.jp \\ ${ }^{*}$ Corresponding author \\ Keywords: \\ cyclic voltammetry; positive electrode materials; rechargeable battery; \\ redox; tetrathiafulvalene
}

Beilstein J. Org. Chem. 2015, 11, 1136-1147. doi:10.3762/bjoc. 11.128

Received: 06 April 2015

Accepted: 19 June 2015

Published: 08 July 2015

This article is part of the Thematic Series "Tetrathiafulvalene chemistry".

Guest Editor: P. J. Skabara

(C) 2015 Iwamoto et al; licensee Beilstein-Institut.

License and terms: see end of document.

\begin{abstract}
Derivatives of tris-fused TTF extended with two ethanediylidenes (5), tris- and pentakis-fused TTFs extended with two thiophene2,5-diylidenes (6-9) were successfully synthesized. Cyclic voltammograms of the tetrakis( $n$-hexylthio) derivative of $\mathbf{5}$ and $\mathbf{7}$ (5d, 7d) consisted of two pairs of two-electron redox waves and two pairs of one-electron redox waves. On the other hand, four pairs of two-electron redox waves and two pairs of one-electron redox waves were observed for the tetrakis( $n$-hexylthio) derivative of 9 (9d). Coin-type cells using the bis(ethylenedithio) derivatives of $\mathbf{5}(\mathbf{5 b}), \mathbf{6}(\mathbf{6 b})$ and the tetrakis(methylthio) derivatives of $\mathbf{5}(\mathbf{5 c})$ and $8(\mathbf{8 c})$ as positive electrode materials showed initial discharge capacities of $157-190 \mathrm{mAh} \mathrm{g}^{-1}$ and initial energy densities of $535-680 \mathrm{mAh} \mathrm{g}^{-1}$. The discharge capacities after 40 cycles were $64-86 \%$ of the initial discharge capacities.
\end{abstract}

\section{Introduction}

Tetrathiafulvalene (TTF, 1a) and its analogues have attracted much attention as potential components for organic functional materials as well as multi-electron redox systems [1-5]. Fused
TTF oligomers [5] are of considerable interest as multi-electron redox systems, because the TTF units strongly interact with each other. For example, a bis-fused TTF, 2,5-bis(1,3-dithiol-3- 
ylidene)-1,3,4,6-tetrathiapentalene (BDT-TTP or simply TTP) exhibits four pairs of one-electron redox waves at $+0.44,+0.62$, +1.05 and $+1.13 \mathrm{~V}$ (V vs SCE, in benzonitrile) [6]. The $E_{2}-E_{1}$ value is considerably larger than most dimeric TTF derivatives linked by $\sigma$-bond (typically $0.05-0.10 \mathrm{~V}$ ) [7]. Fused TTF donors also play important roles in the development of highly functional materials. For example, TTP and its derivatives have yielded a large number of molecular conductors retaining metallic conductivity down to $\leq 4.2 \mathrm{~K}$, because they have a tendency to construct two-dimensional molecular arrays through side-by-side sulfur $\cdots$ sulfur interaction $[5,8]$. On the other hand, a tris-fused TTF, 2,2'-bis[5-(1,3-dithiol-2-ylidene)-1,3,4,6tetrathiapentanylidene] (TTPY, 2a) and its derivatives have afforded highly conducting $\mathrm{SbF}_{6}{ }^{-}$and iodine salts of $\sigma_{\mathrm{rt}} \approx 10^{-1}-10^{1} \mathrm{~S} \mathrm{~cm}^{-1}$ on compressed pellets $[9,10]$.

Recently, we reported that TTP and TTPY can be utilized as positive electrode materials for rechargeable batteries [11]. All organic molecules exhibiting multi-electron redox behaviour seem to be promising as active materials for rechargeable batteries. However, most organic molecules have a crucial disadvantage, that is, they dissolve in organic solvents used for electrolyte solutions. TTF cannot be used as an active electrode material for rechargeable batteries for the above reason, while bis(ethylenedithio)-TTF (BEDT-TTF, 1b) exhibits relatively good charge-discharge cycle performance because of its lower solubility in organic solvents [12]. However, the substitution of two ethylenedithio groups on TTF results in a significant decrease in the theoretical capacity (about half that of TTF). Utilization of polymerized materials is one of the solutions to decrease solubility. However, insertion of a linkage group, which is usually required to construct polymers, also results in considerable decrease in the theoretical capacity [13]. As for fused TTF oligomers, theoretical capacity rather increases as the number of TTF units increases because two carbons are shared in the two TTF units. TTP and TTPY are actually less soluble in organic solvents than TTF. In particular, TTPY is barely soluble in common solvents even in carbon disulfide. However, the maximum electrons cannot be utilized for TTP and TTPY batteries because TTP and TTPY dissolve in the electrolyte solutions in their maximum oxidation states (tetravalent for TTP and hexavalent for TTPY, respectively) [11].

Possible molecular modifications for TTPY to reduce solubility in electrolyte solvents are as follows; (i) introduction of rigid substituents such as the ethylenedithio group as mentioned above, (ii) use of a rigid extended-TTF unit, (iii) increase of the number of (extended) TTF units. As for the modification (ii), insertion of a $\pi$-spacer is sometimes useful. A vinylogous TTF (3, Figure 1) [14-16] shows lower solubility in ordinary organic solvents than TTF, although the thiophene-containing analog (4,
Figure 1) [17-19] is more soluble than TTF. Increase of the TTF units might be the best way; however, the preparation of tetrakis- and/or pentakis-fused TTFs is not easy because of the low solubility of the precursor molecules. Insertion of thiophene spacers is a possible strategy for synthesizing fused TTF oligomers, because thiophene inserted precursors are more soluble than the TTF-type precursors as mentioned above. We succeeded in the synthesis of fused TTF pentamer and heptamer composed of the unit of 4 [20]. In this paper, we report the synthesis and electrochemical properties of vinyl extended TTPY analogue (5b-d) and tris- and pentakis-fused TTF analogues extended by the insertion of two thiophene rings $(\mathbf{6 b}, \mathbf{6 d}, 7 \mathbf{d}, 8 \mathbf{c}$ and 9d). We also report the charge-discharge properties of rechargeable batteries incorporating the methylthio and ethylenedithio derivatives of 5,6 and $8(5 b, 5 c, 6 b$ and $8 c)$ as a positive electrode material.

\section{Results and Discussion Synthesis}

The synthesis of new donors was carried out according to Scheme 1. A trimethylphosphite-mediate cross coupling between a 1,3-dithiole-2-thione (10) [21] and 1,3-dithiol-2-one (11) [22-24] gave a TTF derivative with two ethoxyphosphoryl groups (12) in 63\% yield. We adopted the cross-coupling reaction between the 1,3-dithiole-2-thione and the 1,3-dithiol-2one derivatives for the following reasons. The homo-coupling reaction of $\mathbf{1 0}$ afforded $\mathbf{1 2}$ in low yields, and purification by column chromatography was difficult because of undesired byproducts. The homo-coupling reaction using 11 might give 12 in a good yield, however, toxic and expensive mercury(II) acetate has to be used for the synthesis of 11. Thus, the cross-coupling reaction is useful for saving 11 . The Horner-Wadsworth-Emmons reaction of $\mathbf{1 2}$ with 2 equiv of aldehydes $\mathbf{1 3 b}-\mathbf{d}[16,25]$ in the presence of BuLi in THF at $-78{ }^{\circ} \mathrm{C}$ gave the desired bis-adducts $\mathbf{5 b}-\mathbf{d}$ in $54-85 \%$ yields. Similarly, 6b, 6c, 7d, 8c and 9d were obtained in $62-85 \%$ yields by the reaction of 12 with $\mathbf{1 4 b}, \mathbf{c}, \mathbf{1 5 d}$ [17-19] or $\mathbf{1 6 c}, \mathbf{1 7 d}$ [26] in the presence of BuLi in THF. All the new donors were obtained as stable solids.

\section{Theoretical calculations}

We performed theoretical calculations of $5 \mathrm{~A}, 6 \mathrm{Aa}$ and 7Aa by using the Gaussian 09 program based on the density functional theory (DFT) at the B3LYP/6-31G(d) level [27]. Their HOMO and HOMO $-n$ ( $n=1-2$ and $1-4)$ of the trans isomers of 5a, 6a and 8a are shown in Figures 2-4, respectively. The shapes, energy levels and total energies of the trans and cis isomers were almost the same as each other. The HOMO of 5a was distributed over the whole molecules. Molecular orbital coefficients were largely observed in the vinylogous TTF moieties rather than in the central TTF moiety (Figure 2). In the 
<smiles>[R]C1=C([R])SC(=C2SC([R])=C([R])S2)S1</smiles>

1

1a, TTF

1b, BEDT-TTF<smiles>[R]C1=C([R])SC(=CC=C2SC([R])=C([R])S2)S1</smiles><smiles></smiles>

TTP<smiles>[R]C1=C([R])SC(=Cc2ccc(C=C3SC([R])=C([R])S3)s2)S1</smiles><smiles>[R]C1=C([R])SC(=CC=C2SC3=C(S2)SC(=C2SC4=C(SC(=CC=C5SC([R])=C([R])S5)S4)S2)S3)S1</smiles><smiles>[R]C1=C([R])SC(=C2SC3=C(S2)SC(=C2SC4=C(SC(=C5SC([R])=C([R])S5)S4)S2)S3)S1</smiles>

2a, TTPY
a, $\mathrm{R}=\mathrm{H}$
b, $2 \mathrm{R}=\mathrm{SCH}_{2} \mathrm{CH}_{2} \mathrm{~S}$
c, $\mathrm{R}=\mathrm{SMe}$
d, $\mathrm{R}=\mathrm{S}-n-\mathrm{C}_{6} \mathrm{H}_{13}$
e, $\mathrm{R}=\mathrm{SCH}_{2}\left(\mathrm{C}_{2} \mathrm{H}_{5}\right) \mathrm{CH}_{2} \mathrm{CH}_{2} \mathrm{CH}_{2} \mathrm{CH}_{2} \mathrm{CH}_{3}$<smiles>[R]C1=C([R])SC(=Cc2ccc(C=C3SC4=C(S3)SC(=C3SC5=C(SC(=Cc6ccc(C=C7SC([R])=C([R])S7)s6)S5)S3)S4)s2)S1</smiles>

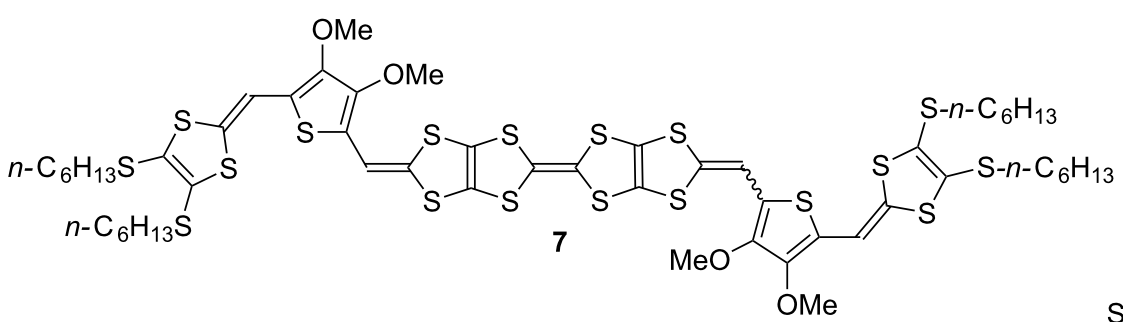

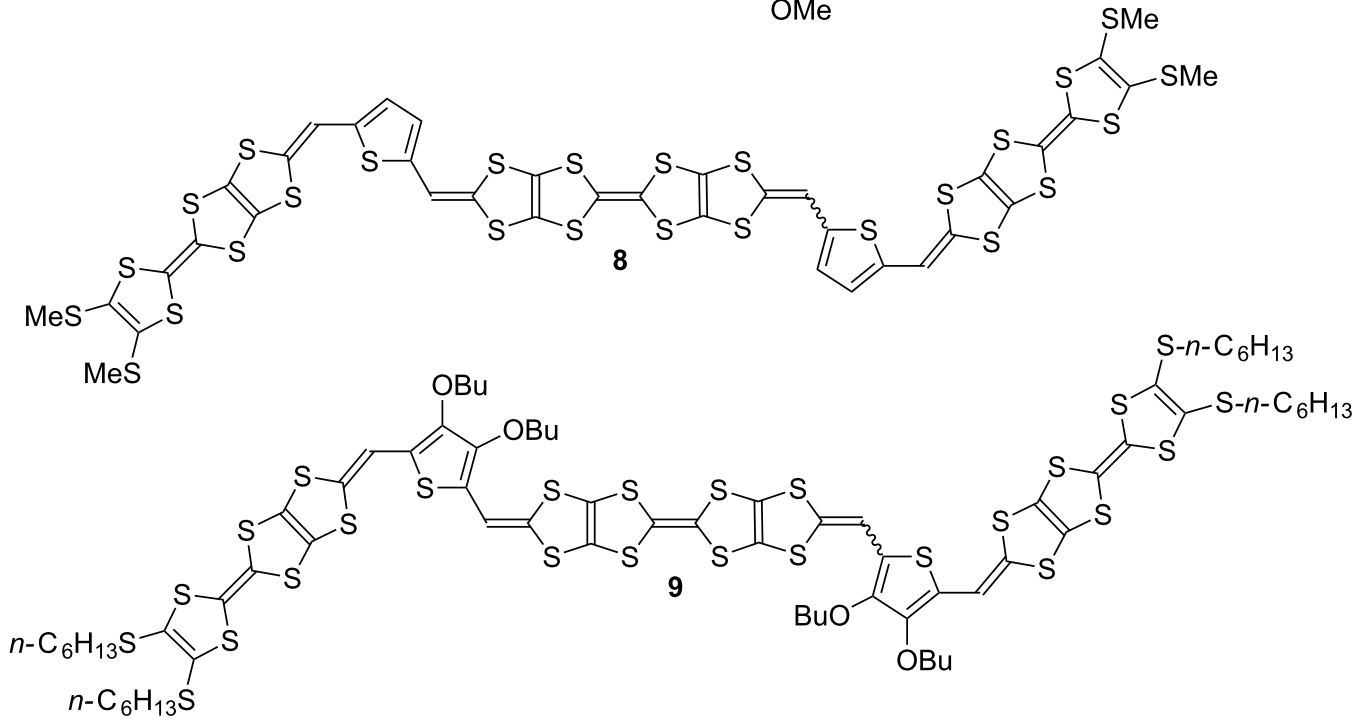

Figure 1: Chemical structures of 1-9 and TTP.

HOMO-1, most molecular orbital coefficients were found on the bilateral vinylogous TTF moieties. The HOMO-2 was mainly located on the central TTF unit. In the bilateral vinylogous TTF moieties, small molecular orbital coefficients were observed. The shapes of the HOMO, HOMO-1 and HOMO-2 of the thiophene extended donor $\mathbf{6 a}$ resembled those of $\mathbf{5 a}$ (Figure 3). The HOMO of 8a spread mainly over the central TTF and the bilateral extended TTF moieties, and the TTF moieties at the both ends barely contributed to the HOMO (Figure 4). Similarly to 6a, larger molecular orbital coefficients 
<smiles>CCO[PH](=O)C1Sc2sc(=S)sc2S1</smiles>
10<smiles>CCOP(=O)(O)C1Sc2sc(=O)sc2S1</smiles>

11
$\stackrel{\mathrm{P}(\mathrm{OMe})_{3}}{\longrightarrow}$<smiles>CCOP(=O)(O)C1SC2=C(SC(=C3SC4=C(S3)SC(P(=O)(OCC)OCC)S4)S2)S1</smiles>

a, $\mathrm{R}=\mathrm{H}$
b, $2 \mathrm{R}=\mathrm{SCH}_{2} \mathrm{CH}_{2} \mathrm{~S}$
c, $\mathrm{R}=\mathrm{SMe}$
d, $\mathrm{R}=\mathrm{S}-n-\mathrm{C}_{6} \mathrm{H}_{13}$
e, $\mathrm{R}=\mathrm{SCH}_{2}\left(\mathrm{C}_{2} \mathrm{H}_{5}\right) \mathrm{CH}_{2} \mathrm{CH}_{2} \mathrm{CH}_{2} \mathrm{CH}_{2} \mathrm{CH}_{3}$

$6 b$

$5 c$

$5 d$

$-78^{\circ} \mathrm{C}$

$6 c$

$-78^{\circ} \mathrm{C}$

$\left.\|_{S}^{S}\right\rangle_{S}^{S}\left\|_{S}^{S}\right\|_{-S}^{S}$

$\underset{\mathrm{THF}}{16 \mathrm{c}\left(\mathrm{R}^{\prime}=\mathrm{H}\right)}$

$-78^{\circ} \mathrm{C}$

\section{HOMO}

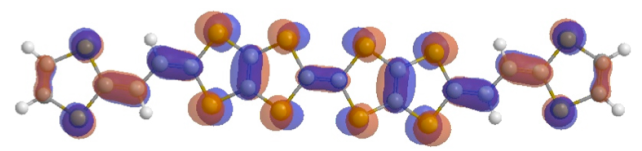

HOMO-1

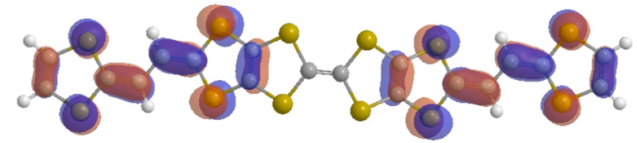

HOMO-2

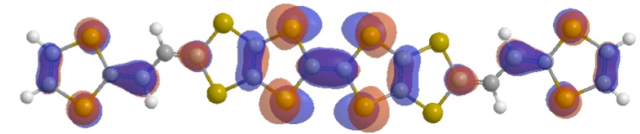

Figure 2: Molecular orbitals of $\mathbf{5 a}$ (trans isomer). of the sulfur atoms were found in the extended TTF moieties of 8a rather than in the central TTF moiety. The HOMO-1 was mainly distributed on the two extended TTF moieties. Small molecular orbital coefficients were observed in the TTF moieties at the both ends. In contrast, the HOMO-2 was hardly distributed on the extended TTF units, but was substantially located on the three TTF units. The TTF moieties at the both ends considerably contributed to the HOMO-3. The HOMO-4 is distributed mainly on the central TTF moiety, although small molecular orbital coefficients were observed in the other donor units.

The orbital energies of the HOMO and HOMO $-n(n=1-2$ and 1-4) for 5a, 6a and $8 \mathbf{a}$ are summarized in Table 1. The orbital energies of HOMO of 5a, 6a and 8a $(-4.532$ to $-4.605 \mathrm{eV})$ are comparable to each other, and are higher by $0.18-0.25 \mathrm{eV}$ than that of TTPY $(-4.787 \mathrm{eV})$. If the oxidation relates to the orbital energy, the first oxidations of 5-9 might occur at lower potentials than TTPY. The energy differences between the HOMO and HOMO-1 of all the donors $(0.041-0.113 \mathrm{eV})$ were smaller 


\section{HOMO}

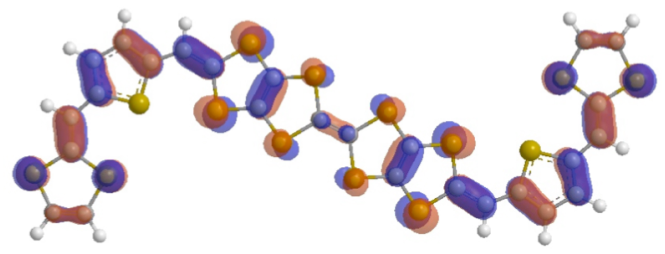

HOMO-1

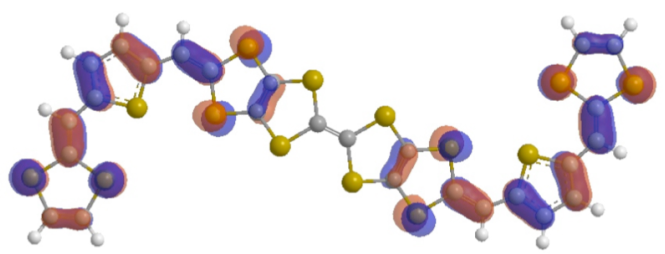

HOMO-2

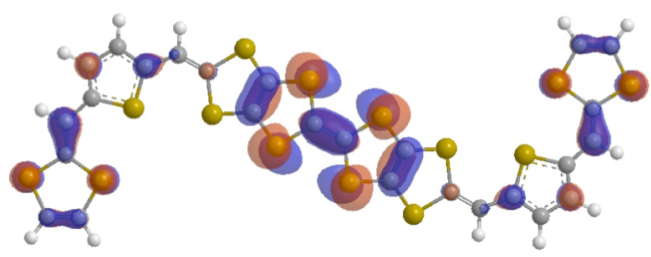

Figure 3: Molecular orbitals of $\mathbf{6 a}$ (trans isomer).

than that of TTPY $(0.186 \mathrm{eV})$. In particular, the orbital energies of the HOMO and HOMO-1 of $\mathbf{8 a}(-4.602$ and $-4.643 \mathrm{eV}$, respectively) were close to each other, suggesting that the first four-electron oxidation of $\mathbf{8 a}$ might occur in a narrow potential range. The HOMO-2 of 5a and 6Aa ( -5.257 and $-5.129 \mathrm{eV}$, respectively) and $\mathrm{HOMO}-4$ of $8 \mathbf{a}(-5.328 \mathrm{eV})$ were slightly higher than the orbital energy of the HOMO-2 of TTPY $(-5.439 \mathrm{eV})$. These results suggest that the electrons at the HOMO-2 of 5a and 6a and HOMO-4 of 8a might be removed more easily than those at the HOMO-2 of TTPY.

Table 1: Orbital energies (eV) of 5a, $6 \mathbf{a}$ and $8 \mathbf{a}$.

\begin{tabular}{lllll} 
& $\mathbf{5 a}$ & $\mathbf{6 a}$ & $\mathbf{8 a}$ & TTPY \\
\hline HOMO & -4.605 & -4.532 & -4.602 & -4.787 \\
HOMO-1 & -4.718 & -4.589 & -4.643 & -4.973 \\
HOMO-2 & -5.257 & -5.129 & -4.967 & -5.439 \\
HOMO-3 & - & - & -5.061 & - \\
HOMO-4 & - & - & -5.328 & -
\end{tabular}

\section{HOMO}

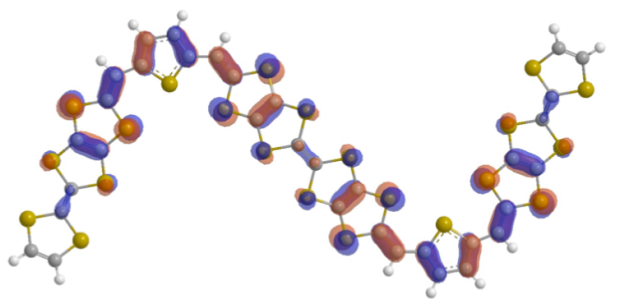

HOMO-1

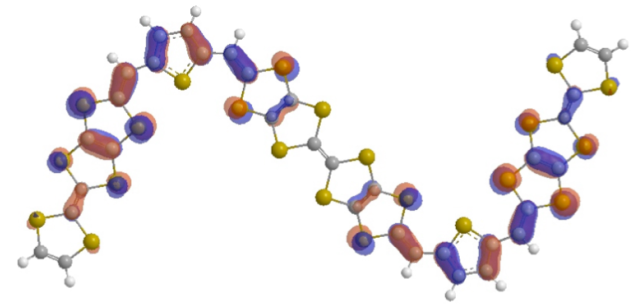

HOMO-2

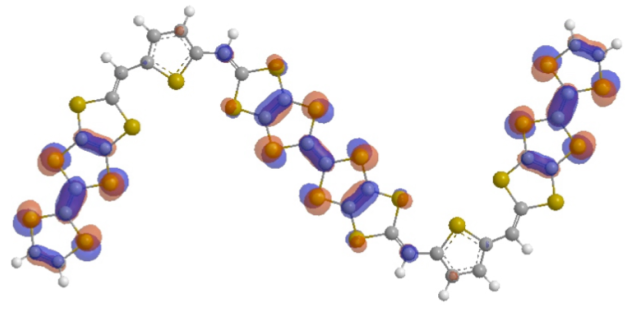

HOMO-3

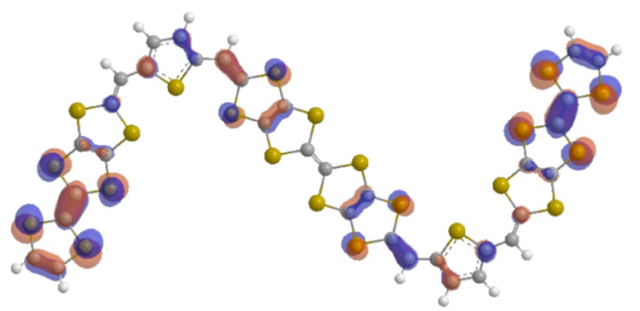

HOMO-4

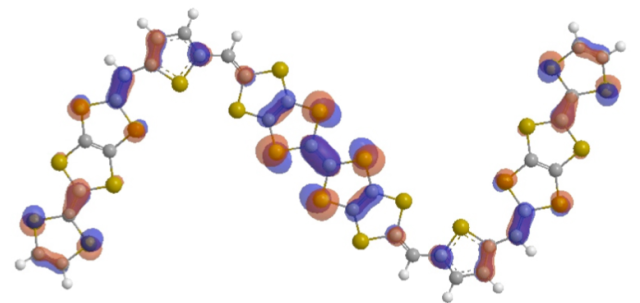

Figure 4: Molecular orbitals of $\mathbf{8 a}$ (trans isomer). 


\section{Electrochemical properties}

The redox behaviors of $\mathbf{5 d}, \mathbf{7 d}$ and $9 \mathbf{d}$ were investigated by using cyclic voltammetry. Deconvoluted cyclic voltammograms of $5 \mathbf{d}, 7 \mathbf{d}$ and $9 \mathbf{d}$ measured in a carbon disulfide/benzonitrile $(1: 1, v / v)$ solution are shown in Figure 5. As for the trisfused donors $\mathbf{5 d}$ and $\mathbf{7 d}$, four pairs of redox waves were observed. The peak currents of the first and second redox waves were about double those of the others. The maximum number of electrons participating in the redox was six, considering that

(a)

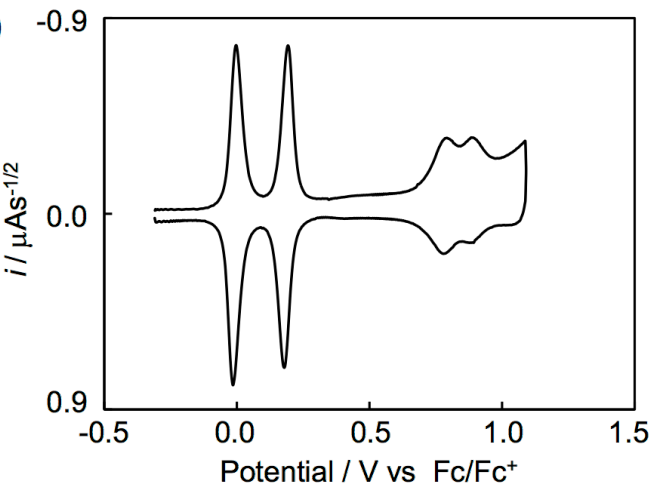

(b)

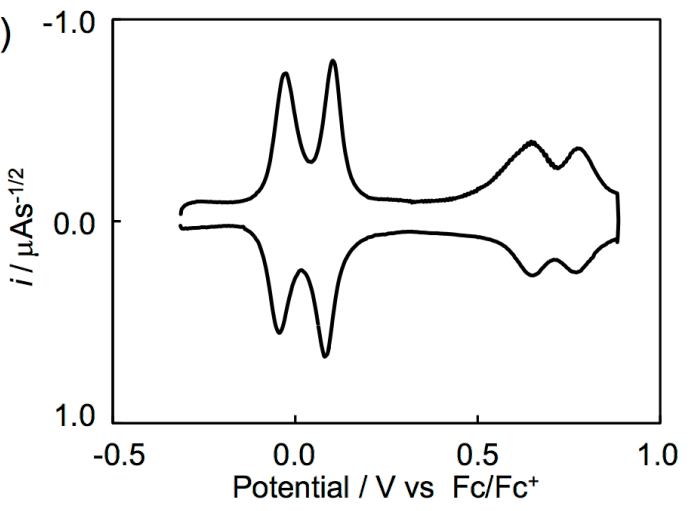

(c)

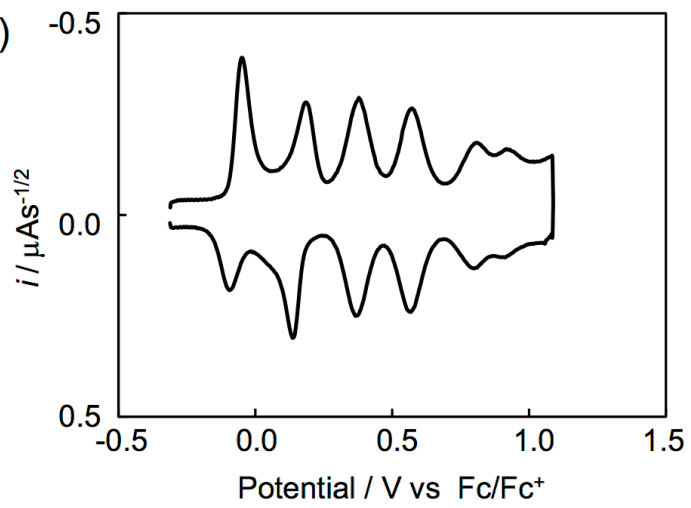

Figure 5: Deconvoluted cyclic voltammograms of (a) $\mathbf{5 d}$, (b) $\mathbf{7 d}$ and (c) 9d. both donors have six redox-active 1,3-dithiol-2-ylidene (DT) sites. Thus, we think that the first and second redox waves correspond to two-electron redox processes and that the remaining waves correspond to one-electron transfer processes. The pentakis-fused donor 9d shows six pairs of redox waves. The peak currents of the last two pairs of redox waves were about half as large as those of the others. Considering that 9d has ten redox-active 1,3-dithiol-2-ylidene sites, it is suggested that the last two pairs of redox waves of $9 \mathbf{d}$ correspond to oneelectron transfer process, while the others correspond to twoelectron transfer processes.

The redox potentials of $\mathbf{5 d}, \mathbf{7 d}$ and $9 \mathbf{d}$ are summarized in Table 2 together with their related compounds. The first twoelectron redox potentials of $\mathbf{5 d}\left(E_{\mathrm{m} 1}=-0.01 \mathrm{~V}\right)$ and $7 \mathbf{d}$ $\left(E_{\mathrm{m} 1}=-0.04 \mathrm{~V}\right)$ were more negative by 0.13 and $0.16 \mathrm{~V}$ than the first redox potential of a TTPY derivative $2 \mathbf{e}\left(E_{1}=+0.12 \mathrm{~V}\right)$ measured under the identical conditions. The first redox waves of $\mathbf{5 d}$ and $7 \mathbf{d}$ involved two-electron transfer processes, and that $E_{1}$ of the extended donors $\mathbf{3 c}$ and $\mathbf{1 8}(-0.06 \mathrm{~V})$ was lower than that of the TTF derivative $1 \mathrm{c}(+0.03 \mathrm{~V})$. These results suggest that two positive charges formed by the first two-electron oxidation process of $\mathbf{5 d}$ and $\mathbf{7 d}$ are presumably distributed mainly on each of the two extended TTF moieties so as to reduce on-site Coulomb repulsion (Scheme 2). Similarly, the two positive charges in $\mathbf{5} \mathbf{d}^{4+}$ and $\mathbf{7} \mathbf{d}^{4+}$ might be located mainly on each of the two extended TTF donors. Observation of two sequent one-electron redox waves in the higher potential region $(+0.6$ to $+0.9 \mathrm{~V}$ ) indicates that the central TTF moiety contributes to the remaining redox processes. The significant positive shifts of the $E_{5}$ and $E_{6}$ of 5d and $7 \mathbf{d}$ by $0.62-0.75 \mathrm{~V}$ and $0.41-0.63 \mathrm{~V}$, respectively, compared to the $E_{1}$ and $E_{2}$ of $3 \mathbf{c}$ is probably due to the strong electron-withdrawing effect by two dicationic extended TTF units in the tetracationic states. In other words, the presence of five and six positive charges in the molecules induces significantly large on-site coulomb repulsion. The $E_{5}$ and $E_{6}$ of $7 \mathbf{d}$ are lower by $0.12-0.14 \mathrm{~V}$ than those of $\mathbf{5 d}$, suggesting that $\mathbf{7} \mathbf{d}^{6+}$ is more stabilized than $\mathbf{5} \mathbf{d}^{6+}$. The thiophene spacers inserted between two cationic 1,3-dithiole rings might reduce the intramolecular coulomb repulsion in $\mathbf{7} \mathbf{d}^{6+}$.

As for $\mathbf{9 d}$, two positive charges in $\mathbf{9} \mathbf{d}^{2+}$ are probably distributed mainly on each of the two thiophene-inserted TTF moieties, since the first redox wave of $9 \mathbf{d}$ corresponds to a simultaneous two-electron transfer process, and the $E_{\mathrm{m} 1}$ $(-0.07 \mathrm{~V})$ is comparable to the $E_{1}$ of $\mathbf{1 8}(-0.06 \mathrm{~V})$ as shown in Scheme 3. The $E_{\mathrm{m} 2}$ of $9 \mathbf{d}(+0.16 \mathrm{~V})$ is lower by $0.20 \mathrm{~V}$ than the $E_{3}$ of $19(+0.36 \mathrm{~V})$ [28], suggesting that the second redox process is contributed by two extended TTF moieties similarly to the first redox process. On the other hand, both the third and fourth redox waves involve two-electron transfer, and their 
Table 2: Redox potentials of $\mathbf{5 d}, \mathbf{7 d}, \mathbf{9 d}$ and their related compounds ( $\mathrm{V}$ vs $\mathrm{Fc} / \mathrm{Fc}^{+}$, in benzonitrile/carbon disulfide 1:1, v/v).

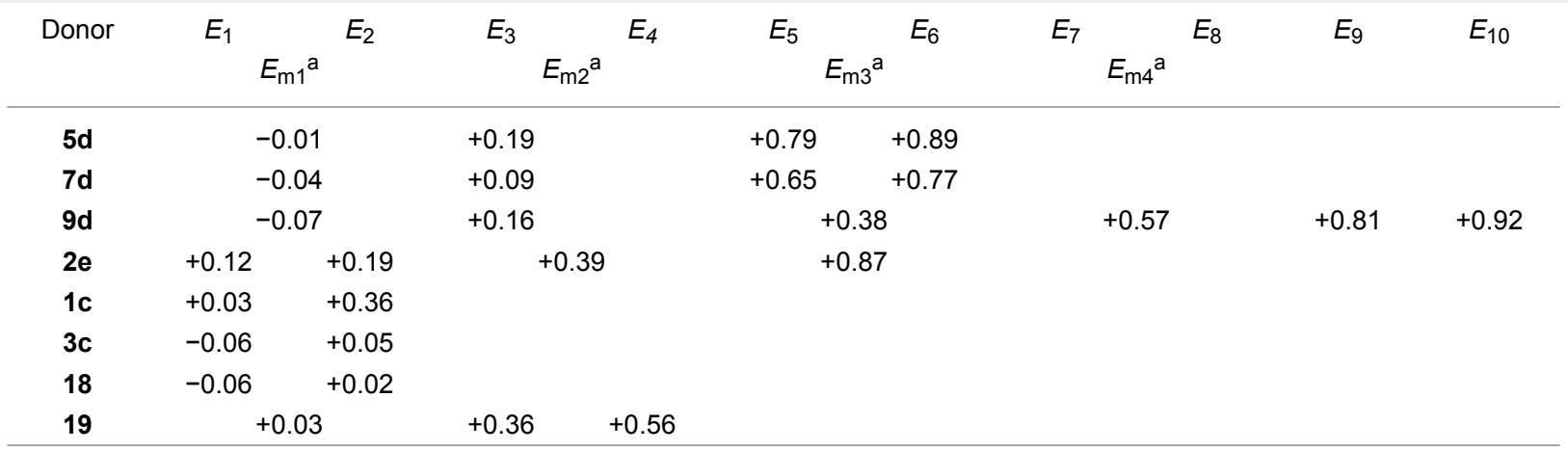

${ }^{\mathrm{a}} E_{\mathrm{m} 1}=\left(E_{1}+E_{2}\right) / 2 . E_{\mathrm{m} 2}=\left(E_{3}+E_{4}\right) / 2 . E_{\mathrm{m} 3}=\left(E_{5}+E_{6}\right) / 2 . E_{\mathrm{m} 4}=\left(E_{7}+E_{8}\right) / 2$.

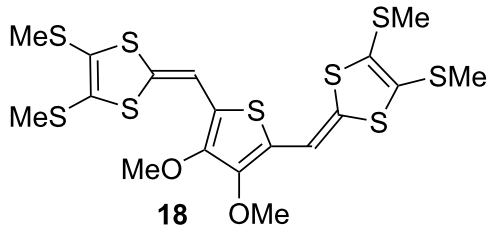

18 OMe

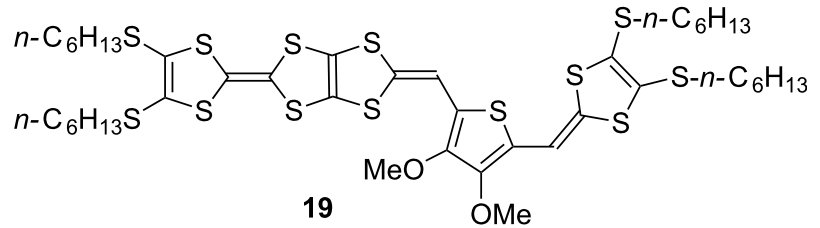

19

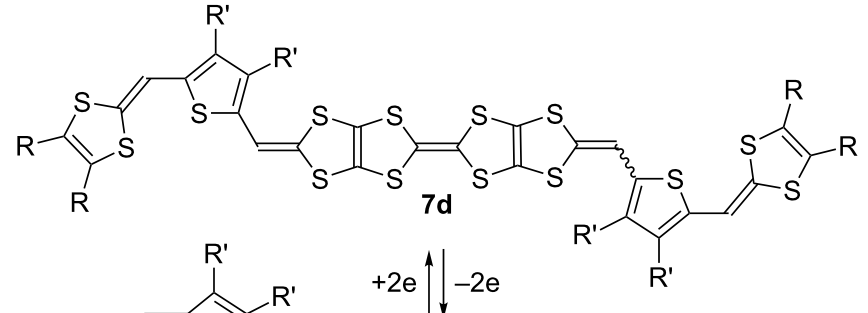

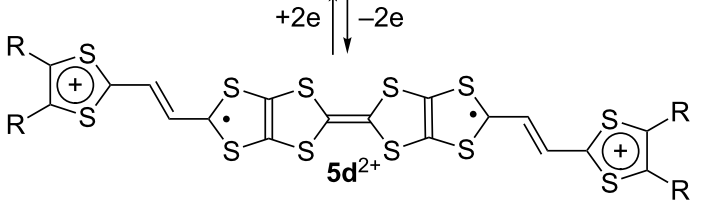
$+2 \mathrm{e} \mid-2 \mathrm{e}$

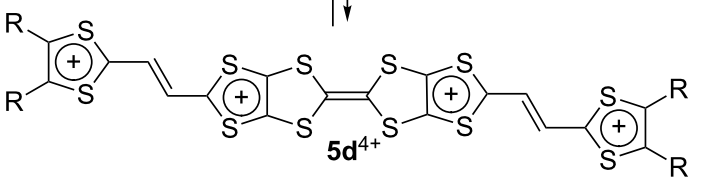
$+\mathrm{e}||^{-\mathrm{e}}$

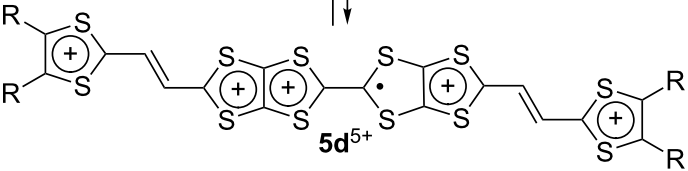<smiles>[R]C=C[Al]</smiles><smiles>[R]c1sc2cc1C2</smiles><smiles>[R]c1ccccc1</smiles><smiles>[R]c1c(C=C)csc1C=C</smiles>
$+2 \mathrm{e} \mid-2 \mathrm{e}$ $\underbrace{S}_{R^{\prime}}$<smiles>[R]c1ccccc1</smiles><smiles></smiles>

$+e \uparrow \mid-e$<smiles></smiles>

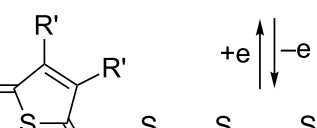

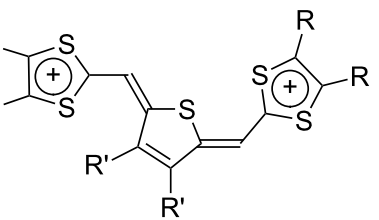

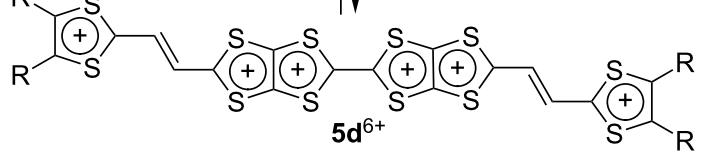<smiles>[R]c1ccccc1I</smiles>

$\mathrm{R}=\mathrm{S}-\mathrm{n}-\mathrm{C}_{6} \mathrm{H}_{13}, \mathrm{R}^{\prime}=\mathrm{OMe}$

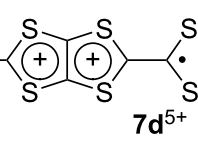

$+\mathrm{e} \mid \mathrm{l}$<smiles>[R]c1cscc1-c1ccccc1</smiles><smiles></smiles>

Scheme 2: Plausible redox processes of $\mathbf{5 d}$ and $\mathbf{7 d}$. 


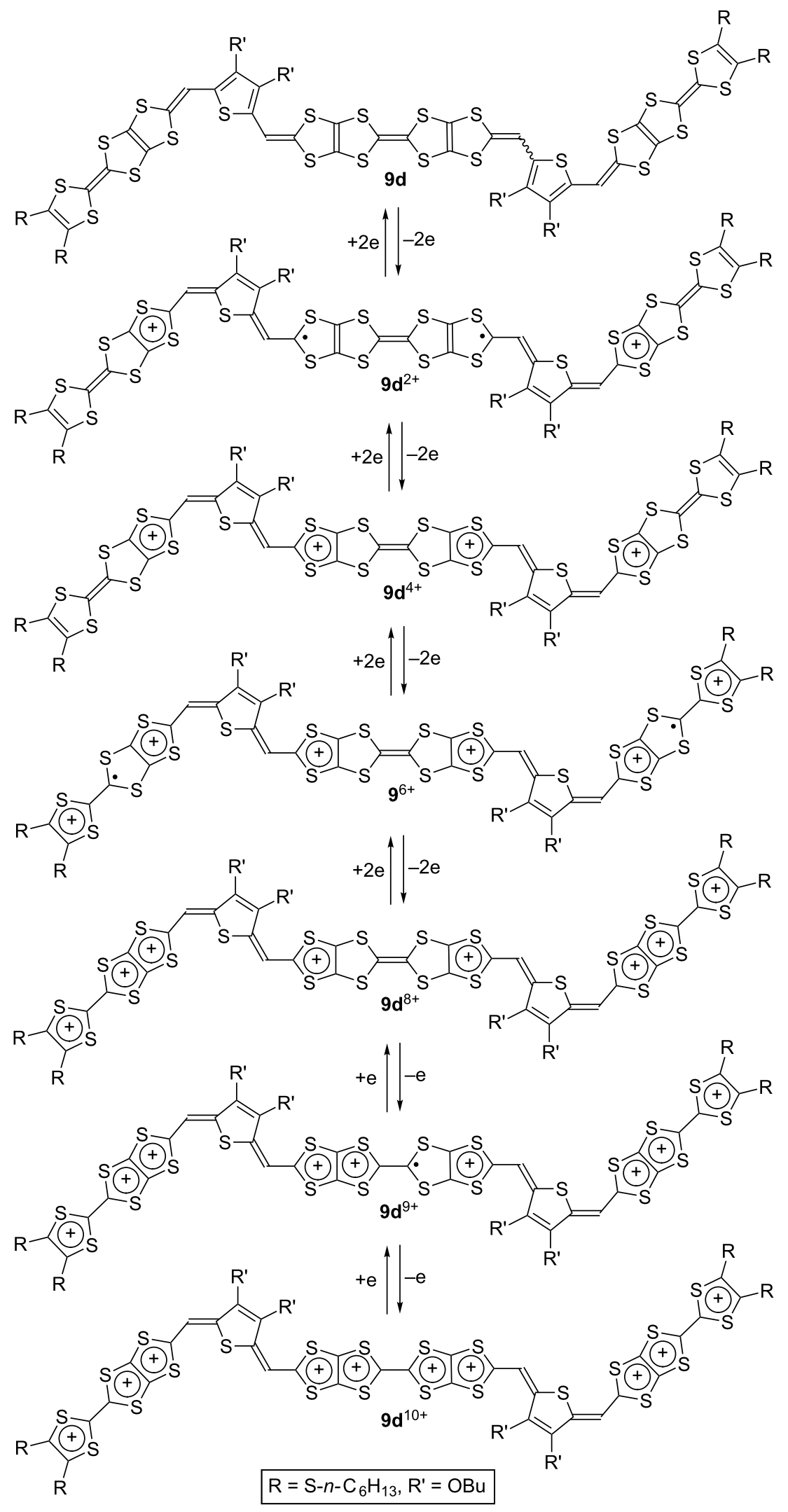


potentials $\left(E_{\mathrm{m} 3}=+0.38 \mathrm{~V}, E_{\mathrm{m} 4}=+0.57 \mathrm{~V}\right.$, respectively) are comparable to the $E_{3}$ and $E_{4}$ of $19\left(E_{3}=+0.36 \mathrm{~V}, E_{4}=+0.56 \mathrm{~V}\right.$, respectively). Therefore, it is indicated that positive charges formed by the third and fourth redox processes are distributed over two TTF moieties at the both ends. The central TTF moiety contributes to the remaining two stages of the one-electron redox processes at +0.81 and $+0.92 \mathrm{~V}$, similarly to $\mathbf{5 d}$ and 7d.

\section{Charge and discharge properties of rechargeable batteries}

In order to examine the cell performance, IEC R2016 coin-type cells were fabricated using a positive electrode incorporating $\mathbf{5}$, $\mathbf{6}$ and $8(5 b, 5 c, 6 b$ and $8 c)$ as positive electrode materials. The applied current densities were $40 \mathrm{~mA} \mathrm{~g}^{-1}(0.2 \mathrm{C}$ rate $)$ and $100 \mathrm{~mA} \mathrm{~g}^{-1}$ (0.5 $\mathrm{C}$ rate), respectively. The nominal charge capacity of a battery or an electrode is expressed as a C-rate. A $0.2 \mathrm{C}$ rate means that the full discharge capacity reached in $5 \mathrm{~h}$. Cyclic voltammetry in the solid state was carried out prior to the charge-discharge test so as to determine the turning back voltage (Supporting Information File 1, Figure S4). The electrodes incorporating $\mathbf{5 b}$ and $\mathbf{5 c}$ exhibited three indistinct oxidation peaks at 3.4, 3.6 V and 4.1 V. Multi-scan cycle voltam- metry revealed a significant decay of redox waves at $4.1 \mathrm{~V}$ presumably due to dissolution of the oxidative species of $\mathbf{5 b}$ and $\mathbf{5 c}$ in the electrolyte solution. In contrast, there was no distinct decay of the redox waves at $3.6 \mathrm{~V}$, suggesting that the oxidative species of $\mathbf{5 b}$ and $\mathbf{5 c}$ formed at $3.6 \mathrm{~V}$ barely dissolved in the electrolyte solution. In contrast, no distinct dissolution was observed for the $6 \mathbf{b}$ and $8 \mathbf{c}$ cells even at $4.2 \mathrm{~V}$. Thus, we determined the turn-back voltages as $3.8 \mathrm{~V}$ for the $\mathbf{5 b}$ and $\mathbf{5 c}$ cells, and $4.2 \mathrm{~V}$ for the $\mathbf{6 b}$ and $\mathbf{8 c}$ cell.

The results are summarized in Table 3 , and the first five charge-discharge curves of $5 \mathbf{b} / \mathrm{Li}$ and $6 \mathbf{b} / \mathrm{Li}$ cells cycled at room temperature are shown in Figure 6. A 5c cell also exhibited charge-discharge curves similar to $5 \mathrm{~b} / \mathrm{Li}$ and $6 \mathrm{~b} / \mathrm{Li}$ cells. No distinct plateau was observed in both the charge and discharge processes for all the cells in spite of observation of well-separated redox waves in a solution. This is possibly due to the apparent overlap of the redox processes in the solid state (see also Figure S4 in Supporting Information File 1) [11]. The initial discharge capacities of $\mathbf{5 b} / \mathrm{Li}, \mathbf{5 c} / \mathrm{Li}$ and $\mathbf{6 b} / \mathrm{Li}$ cells were 157,168 and $158 \mathrm{mAh} \mathrm{g}^{-1}$, respectively. They correspond to 93 and $99 \%$ of the theoretical capacity for the five-electron redox of $\mathbf{5 b}$ and $\mathbf{5 c}$, and $94 \%$ of the theoretical capacity for the six-

\begin{tabular}{|c|c|c|c|c|}
\hline & $5 \mathrm{~b} / \mathrm{Li}$ & $5 \mathrm{c} / \mathrm{Li}$ & 6b/Li & $8 \mathrm{c} / \mathrm{Li}$ \\
\hline $\begin{array}{l}\text { Theoretical capacities for maximum electrons utilization } \\
\text { indicated in parentheses }\left(\mathrm{mAh} \mathrm{g}^{-1}\right) \text {. }\end{array}$ & $203(6)$ & $203(6)$ & $169(6)$ & $205(10)$ \\
\hline $1^{\text {st }}$ Discharge capacity $\left(\mathrm{mAh} \mathrm{g}^{-1}\right)$ & 157 & 168 & 158 & 190 \\
\hline Number of electron per molecule participating discharge & 5 & 5 & 6 & 10 \\
\hline Average voltage for $1^{\text {st }}$ discharge $(\mathrm{V})$ & 3.41 & 3.40 & 3.44 & 3.58 \\
\hline $1^{\text {st }}$ Energy density $\left(\mathrm{mWh} \mathrm{g}^{-1}\right)$ & 535 & 571 & 544 & 680 \\
\hline $40^{\text {th }}$ Discharge capacity $/ 1^{\text {st }}$ discharge capacity (\%) & 86 & 73 & 74 & 64 \\
\hline
\end{tabular}
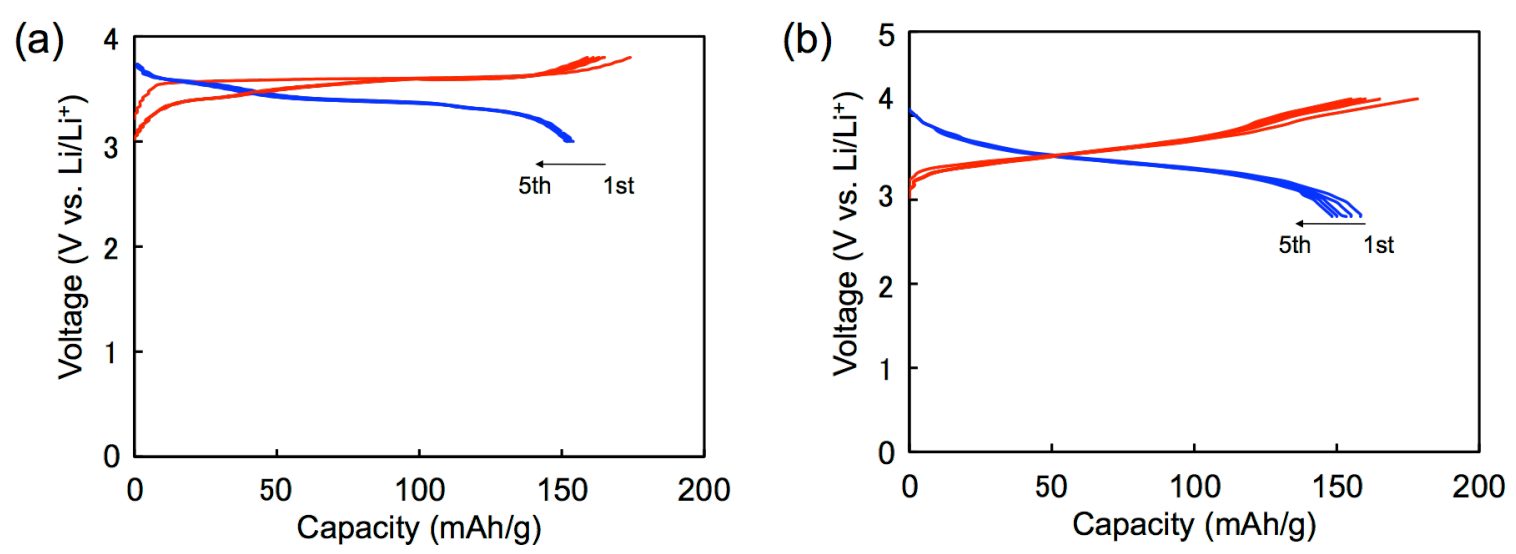

Figure 6: (a) Galvanostatic charge-discharge curves of (a) $5 \mathrm{c} / \mathrm{Li}$ and (b) $6 \mathrm{~b} / \mathrm{Li}$ cells. 
electron redox of $\mathbf{6 b}$, respectively. The first discharge capacities observed are comparable to those of the positive active materials for commercially available lithium ion batteries on the market (150-170 $\mathrm{mAh} \mathrm{g}^{-1}$ ). Cycle-life performances for $5 \mathbf{b} / \mathrm{Li}$, $\mathbf{5 c} / \mathrm{Li}$ and $\mathbf{6 b} / \mathrm{Li}$ cells are shown in Figure 7. In all cases, the discharge capacities decreased gradually as the number of cycles increased. The discharge capacities after 40 cycles were 86,73 and $74 \%$ of the first discharge capacities for $\mathbf{5 b} / \mathrm{Li}, \mathbf{5} \mathbf{c} / \mathrm{Li}$ and $6 \mathbf{b} / \mathrm{Li}$ cells, respectively. The decrease in capacities for the cells using organic electrode materials might be attributed to elution of the positive electrode materials into the electrolyte solution. The result that the $\mathbf{5 b}$ cell shows higher cycle performance than the other cells is consistent with the lower solubility of $\mathbf{5 b}$ with rigid ethylenedithio substituents than $\mathbf{5 c}$ with flexible methylthio substituents.

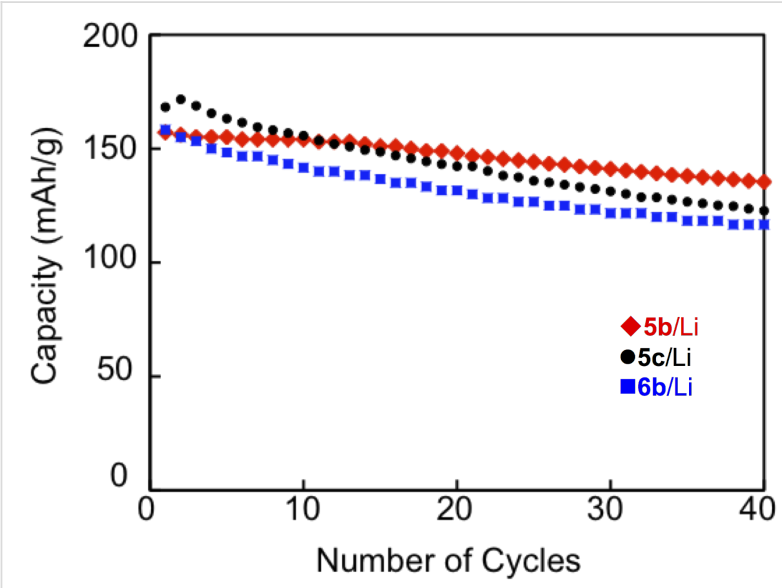

Figure 7: Cycle-life performances for $5 b / \mathrm{Li}, 5 \mathrm{c} / \mathrm{Li}$ and $6 \mathrm{~b} / \mathrm{Li}$ cells

Figure 8 shows the first five charge-discharge curves of a $8 \mathbf{c} / \mathrm{Li}$ cell cycled at room temperature and their cycle performances up to 40 cycles. The initial charge and discharge capacities were
202 and $190 \mathrm{mAh} \mathrm{g}^{-1}$, respectively. They correspond to $99 \%$ and $93 \%$ of the theoretical capacity for ten-electron utilization (205 $\mathrm{mAh} \mathrm{g}^{-1}$ ). This result strongly indicates that ten-electron redox per molecule participates in the charge and discharge processes. Similarly to the $5 \mathbf{b}, 5 \mathbf{c}$ and $6 \mathbf{b}$ cells, the $\mathbf{8 c} / \mathrm{Li}$ cell shows no distinct plateau in both the charge and discharge processes in spite of observation of six pairs of redox waves in a solution. The initial discharge capacity of the $8 \mathrm{c} / \mathrm{Li}$ cell $\left(190 \mathrm{mAh} \mathrm{g}^{-1}\right)$ is higher than those of the cathode active materials for commercially available lithium ion batteries. The discharge capacity after 40 cycles $\left(121 \mathrm{mAh} \mathrm{g}^{-1}\right)$ was $64 \%$ of the first discharge capacity. The high cycle-life performance in spite of utilization of the highest oxidation state of +10 might be because of strong van der Waals force between the large $\pi$-electron frameworks of the thiophene-inserted pentakis-fused TTF.

The energy densities for the first discharge process $\left(1^{\text {st }}\right.$ energy densities) calculated by multiples of the initial discharge capacity and the average voltage are also summarized in Table 3. The first energy densities of $\mathbf{5 b}, \mathbf{5 c}$ and $\mathbf{6 b}$ cells were 535-571 $\mathrm{mWh} \mathrm{g}^{-1}$, which are comparable to that of TTPY (543 $\mathrm{mWh} \mathrm{g}^{-1}$ for four-electron utilization). On the other hand, the first energy density of $\mathbf{8 c}$ cell $\left(680 \mathrm{mWh} \mathrm{g}^{-1}\right)$ is larger which is larger by $110-150 \mathrm{mWh} \mathrm{g}^{-1}$ than those of the others. This value is also superior to the energy densities of most inorganic cathode materials for LIBs [29,30], 20/Li $\left(605 \mathrm{mWh} \mathrm{g}^{-1}\right)$ [31], and is slightly smaller than that of $\mathbf{2 1} / \mathrm{Li}\left(700 \mathrm{mWh} \mathrm{g}^{-1}\right)$ [32] (Figure 9).

\section{Conclusion}

A TTF derivative with two phosphonate groups (12) is a useful building block for the synthesis of odd-numbered fused TTF donors containing extended TTF units. We have demonstrated that some derivatives of $\mathbf{5 , 6}$ and $\mathbf{8}$ can be utilized as positive electrode materials for rechargeable batteries. The $\mathbf{5 b} / \mathrm{Li}$ cell (a)

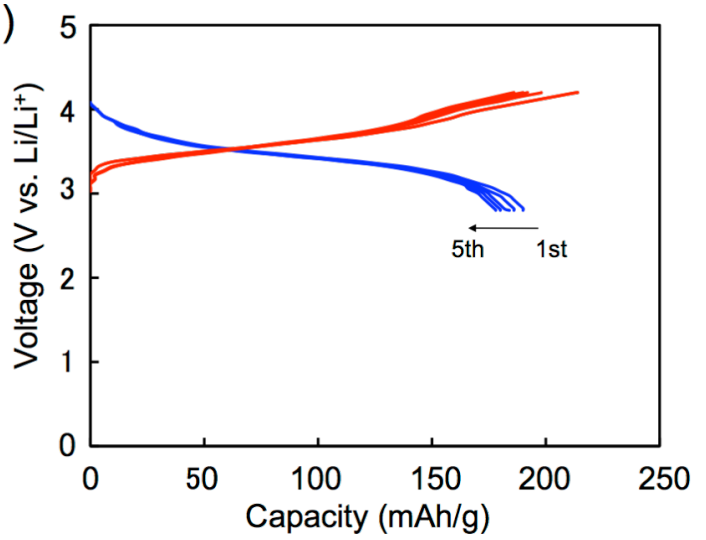

(b)

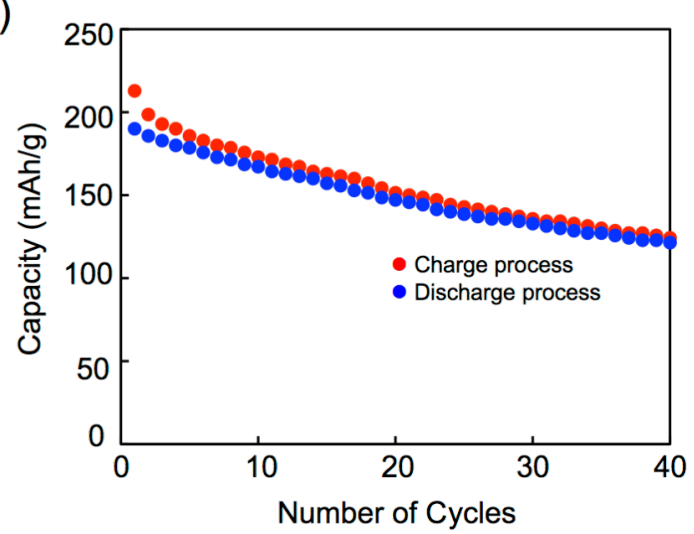

Figure 8: (a) Galvanostatic charge-discharge curves, and (b) cycle-life performances for a 8c/Li cell. 

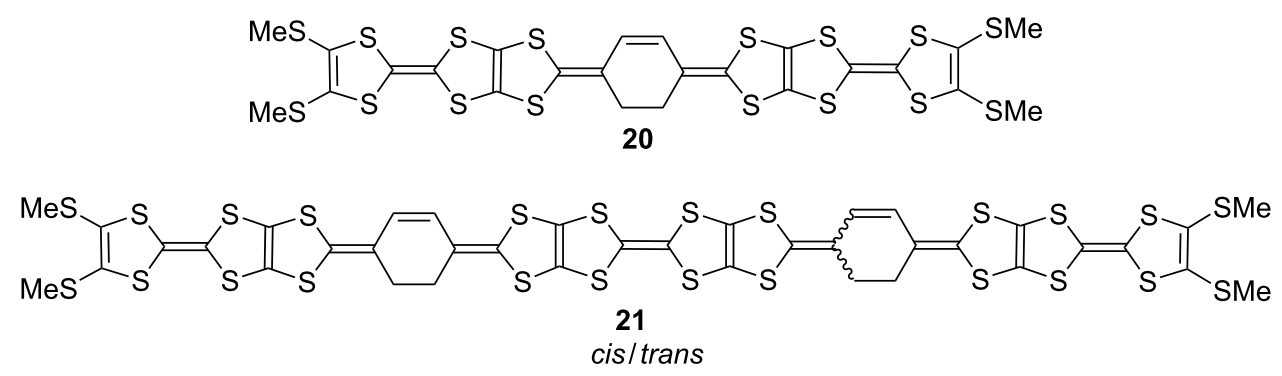

Figure 9: Molecular structures of 20 and 21.

showed considerably higher cycle performance when the number of electrons is suppressed to five per molecule $(5 / 6$ of the maximum electrons). It is noted that the $\mathbf{6 b}$ and $\mathbf{8 c}$ cells showed good cycle performance in spite of utilizing the maximum amounts of electrons (six and ten electrons, respectively). The $\mathbf{8 c}$ cell exhibited significantly high energy density $\left(680 \mathrm{mWh} \mathrm{g}^{-1}\right)$ at the first discharge thanks to ten electrons utilization. The information obtained from the present work could be helpful in the molecular design and synthesis of new positive electrode materials for rechargeable batteries. We are engaged in the synthesis of the other derivatives of 5, 6 and 8 containing unsubstituted derivatives and higher homologues of 5, which are expected to exhibit higher charge-discharge performance than the materials described in this paper.

\section{Supporting Information}

\section{Supporting Information File 1}

Experimental details and spectroscopic data, optimized structures of 5a, 6a and 8a (trans isomers) and cycle-life performances for rechargeable batteries using $\mathbf{5 c}, \mathbf{5 b}$ and 6b.

[http://www.beilstein-journals.org/bjoc/content/ supplementary/1860-5397-11-128-S1.pdf]

\section{Acknowledgements}

This work is partially supported by a Grant-in-Aid for Scientific Research (No. 23550155), from the Ministry of Education, Culture, Sports, Science and Technology (MEXT), Japan, MEXT program "Elements Strategy Initiative to Form Core Research Center" (since 2012), and Grant-in-Aid for Research Promotion, Ehime University.

\section{References}

1. Yamada, J.; Sugimoto, T., Eds. TTF Chemistry-Fundamental and Applications of Tetrathiafulvalene; Kodansha-Springer: Tokyo, 2004.

2. Canevet, D.; Sallé, M.; Zhang, G.; Zhang, D.; Zhu, D. Chem. Commun. 2009, 2245-2269. doi:10.1039/b818607n
3. Segura, J. L.; Martín, N. Angew. Chem., Int. Ed. 2001, 40, 1372-1409. doi:10.1002/1521-3773(20010417)40:8<1372::AID-ANIE1372>3.0.CO; 2-I

4. Gorgues, A.; Hudhomme, P.; Sallé, M. Chem. Rev. 2004, 104, 5151-5184. doi:10.1021/cr0306485

5. Misaki, Y. Sci. Technol. Adv. Mater. 2009, 10, 024301. doi:10.1088/1468-6996/10/2/024301

6. Misaki, Y.; Matsui, T.; Kawakami, K.; Nishikawa, H.; Yamabe, T.; Shiro, M. Chem. Lett. 1993, 22, 1337-1340. doi:10.1246/cl.1993.1337

7. Iyoda, M.; Hasegawa, M.; Miyake, Y. Chem. Rev. 2004, 104, 5085-5114. doi:10.1021/cr030651o

8. Misaki, Y.; Fujiwara, H.; Yamabe, T.; Mori, T.; Mori, H.; Tanaka, S. Chem. Lett. 1994, 23, 1653-1656. doi:10.1246/cl.1994.1653

9. Nishikawa, H.; Kawauchi, S.; Misaki, Y.; Yamabe, T. Chem. Lett. 1996, 25, 43-44. doi:10.1246/cl.1996.43

10. Misaki, Y.; Kawakami, K.; Higuchi, N.; Nishikawa, H.; Yamabe, T. Mol. Cryst. Liq. Cryst. Sci. Technol., Sect. A 1996, 284, 337-344. doi:10.1080/10587259608037936

11. Inatomi, Y.; Hojo, N.; Yamamoto, T.; Watanabe, S.; Misaki, Y. ChemPlusChem 2012, 77, 973-976. doi:10.1002/cplu.201200197

12. Inatomi, Y.; Hojo, N.; Yamamoto, T.; Shimada, M.; Watanabe, S. presentation No. 167. In ECS Meeting Abstracts 2008, MA2008-1, 213th ECS meeting, Phoenix, May 22, 2008; The Electrochemical Society.

13. Oyaizu, K.; Suga, T.; Yoshimura, K.; Nishide, H. Macromolecules 2008, 41, 6646-6652. doi:10.1021/ma702576z

14. Yoshida, Z.; Kawase, T.; Awaji, H.; Sugimoto, I.; Sugimoto, T.; Yoneda, S. Tetrahedron Lett. 1983, 24, 3469-3472. doi:10.1016/S0040-4039(00)86015-3

15. Sugimoto, T.; Awaji, H.; Sugimoto, I.; Misaki, Y.; Kawase, T.; Yoneda, S.; Yoshida, Z.; Kobayashi, T.; Anzai, H. Chem. Mater. 1989, 1, 535-547. doi:10.1021/cm00005a015

16. Moore, A. J.; Bryce, M. R.; Ando, D. J.; Hursthouse, M. B. J. Chem. Soc., Chem. Commun. 1991, 320-322. doi:10.1039/c39910000320

17. Hansen, T. K.; Lakshmikantham, M. V.; Cava, M. P.; Niziurski-Mann, R. E.; Jensen, F.; Becher, J. J. Am. Chem. Soc. 1992, 114, 5035-5039. doi:10.1021/ja00039a013

18. Takahashi, K.; Nihira, T.; Yoshifuji, M.; Tomitani, K. Bull. Chem. Soc. Jpn. 1993, 66, 2330-2334. doi:10.1246/bcsj.66.2330

19. Benahmed-Gasmi, A. S.; Frère, P.; Garrigues, B.; Gorgues, A.; Jubault, M.; Carlier, R.; Texier, F. Tetrahedron Lett. 1992, 33, 6457-6460. doi:10.1016/S0040-4039(00)79014-9

20. Misaki, Y.; Kubo, A.; Matsuda, W.; Fueno, H.; Tanaka, K. Curr. Appl. Phys. 2006, 6, 934-938. doi:10.1016/j.cap.2005.01.043 
21. Misaki, Y.; Nishikawa, H.; Kawakami, K.; Uehara, T.; Yamabe, T. Tetrahedron Lett. 1992, 33, 4321-4324. doi:10.1016/S0040-4039(00)74250-X

22. Misaki, Y.; Higuchi, N.; Fujiwara, H.; Yamabe, T.; Mori, T.; Mori, H.; Tanaka, S. Angew. Chem., Int. Ed. Engl. 1995, 34, 1222-1225. doi:10.1002/anie.199512221

23. Misaki, Y.; Ohta, T.; Higuchi, N.; Fujiwara, H.; Yamabe, T.; Mori, T.; Mori, H.; Tanaka, S. J. Mater. Chem. 1995, 5, 1571-1579. doi:10.1039/jm9950501571

24. Takahashi, K.; Tanioka, H.; Fueno, H.; Misaki, Y.; Tanaka, K. Chem. Lett. 2002, 31, 1002-1003. doi:10.1246/cl.2002.1002

25. Moore, A. J.; Bryce, M. R. Tetrahedron Lett. 1992, 33, 1373-1376. doi:10.1016/S0040-4039(00)91626-5

26. Nakamura, K.; Shirahata, T.; Miyamoto, H.; Misaki, Y. Heterocycles 2011, 83, 2115-2126. doi:10.3987/COM-11-12277

27. Gaussian 09, Revision C.01; Gaussian, Inc.: Wallingford, CT, 2009.

28. Misaki, Y.; Sasaki, T.; Ohta, T.; Fujiwara, H.; Yamabe, T. Adv. Mater. 1996, 8, 804-807. doi:10.1002/adma.19960081006

29. Aravindan, V.; Gnanaraj, J.; Lee, Y.-S.; Madhavi, S. J. Mater. Chem. A 2013, 1, 3518-3539. doi:10.1039/c2ta01393b

30. Thackeray, M. M.; Wolverton, C.; Isaacs, E. D. Energy Environ. Sci. 2012, 5, 7854-7863. doi:10.1039/c2ee21892e

31. Kato, M.; Ogi, D.; Yao, M.; Misaki, Y. Chem. Lett. 2013, 42, 1556-1558. doi:10.1246/cl.130841

32. Kato, M.; Senoo, K.; Yao, M.; Misaki, Y. J. Mater. Chem. A 2014, 2 6747-6754. doi:10.1039/c3ta14920j

\section{License and Terms}

This is an Open Access article under the terms of the Creative Commons Attribution License

(http://creativecommons.org/licenses/by/2.0), which permits unrestricted use, distribution, and reproduction in any medium, provided the original work is properly cited.

The license is subject to the Beilstein Journal of Organic Chemistry terms and conditions:

(http://www.beilstein-journals.org/bjoc)

The definitive version of this article is the electronic one which can be found at:

doi:10.3762/bjoc. 11.128 